\title{
Contribution of re-regulation reservoirs considering pumping capability to environmentally friendly hydropower operation
}

\author{
J.I. Pérez-Díaz ${ }^{a, *}$, R. Millán ${ }^{b}$, D. García ${ }^{b}, I_{\text {Guisández }}{ }^{a}$, J.R. Wilhelmi ${ }^{a}$ \\ ${ }^{a}$ Department of Hydraulic and Energy Engineering, Technical University of Madrid (UPM), c/Profesor Aranguren s/n, 28040 Madrid, Spain \\ b.E.G. Hidroelectrica, S.L. c/ Monforte de Lemos $718^{\circ} \mathrm{C}, 28029$ Madrid, Spain ${ }^{\prime}$
}

\begin{abstract}
A B S T R A C T
Environmental constraints imposed on hydropower operation are usually given in the form of minimum environmental flows and maximum and minimum rates of change of flows, or ramp rates. One solution proposed to mitigate the environmental impact caused by the flows discharged by a hydropower plant while reducing the economic impact of the above-mentioned constraints consists in building a reregulation reservoir, or afterbay, downstream of the power plant. Adding pumping capability between the re-regulation reservoir and the main one could contribute both to reducing the size of the reregulation reservoir, with the consequent environmental improvement, and to improving the economic feasibility of the project, always fulfilling the environmental constraints imposed to hydropower operation. The objective of this paper is studying the contribution of a re-regulation reservoir to fulfilling the environmental constraints while reducing the economic impact of said constraints. For that purpose, a revenue-driven optimization model based on mixed integer linear programming is used. Additionally, the advantages of adding pumping capability are analysed. In order to illustrate the applicability of the methodology, a case study based on a real hydropower plant is presented.
\end{abstract}

\section{Introduction}

On September 10th, 2008 the Ministerial Order ARM/2656/2008 came into force in the Spanish legal system. With this Order, the Instructions for hydrological planning are approved. The purpose of these instructions is to establish the necessary criteria for elaborating the river basin management plans [1]. The Order requires the establishment of environmental flows regimes in all Spanish rivers in order to maintain the functionality and structure of the aquatic and riparian ecosystems. Said environmental flows regime will not be considered as a use but as a constraint, imposed to every water use. In order to achieve this goal, the environmental flow regimes shall include, among other things, the minimum flows necessary to maintain the spatial diversity of habitat and connectivity and the maximum allowable rates of change of flows (ramp rates).

As it is well-known, most electricity markets are based on a dayahead wholesale market, where there may occur significant differences between peak and off-peak prices, as it is the case of Italy, France, Germany or Spain, among others. Therefore, peak hydropower plants usually supply power during peak hours and shut-down or operate at low load during off-peak hours. This operation regime is referred to in the technical literature as hydropeaking [2]. One of the negative effects of the environmental constraints is that they reduce the capability of the hydropower plant to adapt its production to the energy prices profile; in this context, it is worth to note that hourly market prices are signals, or indexes, that reflect the benefits that each generated $\mathrm{kWh}$ provides to the electric system operation; these benefits result in avoided costs, reduction in $\mathrm{CO}_{2}$ emissions, etc. In addition, the fulfilment of maximum and minimum ramp rates limits the contribution of peak hydropower plants to adapting the power supply to the demand and to providing important ancillary services to the electrical grid. These functions shall therefore be carried out by other power plants, very likely thermal, which may cause a significant increase in both electric system operating costs and greenhouse gases emissions.

The economic impact of some environmental constraints has been assessed in [3-6] by means of different approaches. In [3], the decrease in the economic value of hydropower is estimated by means of a peak-shaving algorithm with hourly varying market prices. The authors of that study stated that restrictions on maximum and minimum flows, hourly ramp rates and daily flow changes may cause a decrease in the annual economic value of 
hydropower. In [4], the reduction in the annual benefit of the hydropower producer is calculated as the annual cost of the necessary replacement power supplied by thermal power plants; authors conclude that the air quality and recreational fishing benefits were more than twice as large as the economic impact on the hydropower operation. In [5], the decrease in the hydropower profits is calculated by means of an optimal scheduling model based on nonlinear programming. The decrease in hydropower profits due to the fulfilment of ramp rates ranged from less than 2 to by $8 \%$ in the cases analysed in that study. Nevertheless, authors conclude that the total hydro production increased as a result of the ramp constraints, which results in an environmental benefit from reduced air pollution emissions. Other remarkable conclusion is that, in some cases, as the ramp rates become more restrictive the environmental benefit increase at a slightly higher rate than the restriction cost for the hydropower producer and is always higher than the latter. In [6], the decrease in hydropower revenue is calculated by means of a mixed integer linear programming model; the decrease in revenue due to the fulfilment of minimum environmental flows and ramp rates was of the same order of magnitude as that reported in [5].

One of the solutions proposed in the technical literature for mitigating the environmental impact caused by hydropeaking consists in building re-regulation reservoirs, or afterbays, right downstream of the power plant draught tube [7]. The contribution of re-regulation reservoirs to reducing the economic impact of certain environmental constraints was studied in [8], by means of an optimal daily scheduling model based on linear programming. In order to incorporate hourly prices variability into studies with longer time horizons, the author proposed a method based on the price duration curve that avoids the necessity of dividing the time horizon into hourly stages and, therefore, reduces considerably the computational burden of the problem. However, that method does not allow considering in longer time frames the fulfilment of the maximum ramping rate requirement; the method can be also found in [9].

Pumped storage facilities were proposed also in [7] to help reduce the impacts caused by hydropeaking on natural flow patterns. Adding pumping capability between the afterbay and the main reservoir could contribute to reducing both the size of the afterbay (and thus its environmental impact) and the economic impact due to the fulfilment of the environmental constraints. However, the degree to which it could contribute to reduce these impacts, or the economic impact of an existing hydropower plant in which a certain pumping capability was added, was not analysed in [7]. Actually, to authors' knowledge, there is no previous work in which the addition of pumping capability to an existing hydropower plant as a means to reduce the economic impact of the environmental constraints has been analysed in detail. A somewhat related study that is worth mentioning is that presented in [10], where a pumped-storage and thermal unit commitment is solved with the aim of minimizing both costs and greenhouse gases emissions.

The objective of this paper is studying, on one hand, the contribution of re-regulation reservoirs to reducing the economic impact of certain environmental constraints imposed on the operation of a hydropower plant and, on the other hand, the advantages that could be obtained by adding pumping capability between the re-regulation reservoir and the main one. For these purposes, several revenue-driven optimization models similar to that proposed in [11] are used. The proposed approach to consider the addition of pumping capability in the re-regulation reservoir is similar to that presented in [12]. The modelling approach used in the paper is consistent with the purpose of providing good estimates within a time frame adequate for making investments decisions, e.g. one year. Although there exist in the technical literature more detailed optimal scheduling models $[13,14]$, some of which considering discharge ramping constraints [15], the proposed approach is considered to be accurate enough to achieve the above-mentioned objective. In order to illustrate the applicability of the methodology a case study based on a real hydropower plant is presented.

The contribution of this paper with respect to previous works lies in two main issues: the consideration of the pumping capability as a means to reduce the economic impact of the environmental constraints; and the use of detailed models to provide good estimates of the contribution of both the re-regulation reservoir and the pumping capability to reducing the economic impact of the environmental constraints, within a time frame adequate for making investments decisions.

\section{Optimization models}

Four different revenue-driven optimization models have been developed in order to fulfil the objectives of this paper. The first one calculates the optimal operation of the hydropower plant without considering any environmental constraint; the second one calculates the optimal operation of the hydropower plant while fulfilling the minimum environmental flow and maximum ramp rate constraints; the third one considers the existence of a re-regulation reservoir right downstream of the main reservoir as well as the possibility of controlling the water discharges from the reregulation reservoir by varying the opening of its bottom outlet; and the last one considers the addition of pumping capability between both reservoirs. A time horizon of one month divided into hourly time periods is used in all optimization models. All models are based on mixed integer linear programming and consider the option of starting-up or shutting-down the plant in any period of the time horizon and that of releasing water through the bottom outlets of the main reservoir. The option of starting-up or shuttingdown the pump is considered in the fourth model. The hourly water inflows and the reservoir volumes at the beginning of the time horizon are considered in all cases as deterministic variables.

The equations corresponding to each model are as follows:

- Model 1: (1), (3)-(6), (7), (11), (19), (20).

- Model 2: (1), (3)-(6), (7), (11), (13)-(15), (19), (20).

- Model 3: (1), (3)-(6), (7), (8), (11), (12), (16)-(18), (19)-(23).

- Model 4: (2)-(6), (9)-(12), (16)-(18), (19)-(27).

For a given pair of minimum environmental flow and maximum ramp rate, the economic impact caused by the fulfilment of these constraints as well as the contribution of both the re-regulation reservoir and the pumping capability to reducing said impact, will be assessed from comparing to each other the results of the four models.

\subsection{Objective function}

The objective function of the four models consists in maximizing the revenue obtained from selling energy in the day-ahead electricity market (1). In the cases where pumping capability is considered the objective function is given by (2).

$$
\begin{aligned}
& \text { Maximize } Z=\sum_{t=1}^{T} \pi_{t} p_{t}\left(q_{t}, v_{t}\right) \\
& \text { Maximize } Z=\sum_{t=1}^{T} \pi_{t}\left[p_{t}\left(q_{t}, v_{t}\right)-p p_{t}\left(q p_{t}\right)\right]
\end{aligned}
$$




\subsection{Constraints}

\subsubsection{Plan generation characteristic model}

The term 'plant generation characteristic' usually refers to the existing relationship among the water discharged through the turbines, the reservoir volume and the output power. A set of points belonging to said characteristic can be obtained from the turbines efficiency hill curves, the reservoir curve (height-volume relationship), and the tail water level variation and head losses in the conduits, both as a function of the water discharged through the turbines $[16,17]$. In this paper, the influence of the head (or reservoir volume) variation on the power output is ignored during the optimization process; i.e. a generation characteristic model that depends linearly on the flow has been used (3)-(6). This approximation may be considered valid in the case of large reservoirs, where the difference between the minimum and maximum gross heads is small in comparison with the design gross head [18]. Also, it has been assumed that the hydropower plant comprises only one generating unit. A piece-wise linear curve should be used in the case that the power plant comprised two or more generating units [13]. A binary variable, $u_{t}$, has been included in order to consider the option of starting-up and shutting-down the plant.

$p_{t}=u_{t} p_{\min }+r \cdot q t r_{t} ; \forall t=1, \ldots, T$

$q t r_{t} \leq u_{t} l t r ; \forall t=1, \ldots, T$

$q_{t} \leq u_{t} q_{\min }+q t r_{t} ; \forall t=1, \ldots, T$

$u_{t} \in\{0,1\} ; \forall t=1, \ldots, T$

\subsubsection{Reservoir water balance}

The water content of the reservoir at the end of period $t$ must be equal to its water content at the end of period $t-1$ plus the water inflow minus the flow released through the turbines and bottom outlets (7). In the cases where the re-regulation reservoir is considered, the water content of the re-regulation reservoir at the end of period $t$ must be equal to its water content at the end of period $t-1$ plus the flow released through the turbines (from the main reservoir), minus the flow released through the bottom outlets of the re-regulation reservoir (8). In the cases where the addition of pumping capability is considered, the water balance equations are given by (9)-(10).

$$
\begin{aligned}
& v_{t}=v_{t-1}+f_{c}\left(w_{t}-q_{t}-s_{t}\right) \quad \forall t=1, \ldots, T \\
& v r_{t}=v r_{t-1}+f_{c}\left(q_{t}-s r_{t}\right) \quad \forall t=1, \ldots, T \\
& v_{t}=v_{t-1}+f_{c}\left(w_{t}-q_{t}+q p_{t}\right) \quad \forall t=1, \ldots, T \\
& v r_{t}=v r_{t-1}+f_{c}\left(q_{t}-s r_{t}-q p_{t}\right) \quad \forall t=1, \ldots, T
\end{aligned}
$$

\subsubsection{Initial and final reservoir volumes}

The initial and final reservoir volumes are assumed to be known (11). In the cases where the re-regulation reservoir is considered, its initial and final volumes are also assumed to be known (12).

$v_{0}=V_{0}, v_{T}=V_{T}$

$v r_{0}=V r_{0}, v r_{T}=V r_{T}$

\subsubsection{Environmental constraints}

The environmental constraints considered in this paper are: minimum environmental flow (13), and maximum and minimum rates of change of flows discharged to the river, or ramp rates, (14)-(15). It is important to note that in the cases where the reregulation reservoir is considered, the environmental constraints are applied to the discharges released from the re-regulation reservoir (16)-(18).

$$
\begin{aligned}
& q_{t}+s_{t} \geq q_{\mathrm{ec}} ; \quad \forall t=1, \ldots, T \\
& \left(q_{t}+s_{t}\right)-\left(q_{t-1}+s_{t-1}\right) \leq \mathrm{d} q^{\max } ; \quad \forall t=1, \ldots, T \\
& \left(q_{t}+s_{t}\right)-\left(q_{t-1}+s_{t-1}\right) \geq-\mathrm{d} q^{\max } ; \quad \forall t=1, \ldots, T \\
& s r_{t} \geq q_{\mathrm{ec}} ; \quad \forall t=1, \ldots, T \\
& s r_{t}-s r_{t-1} \leq \mathrm{d} q^{\max } ; \quad \forall t=1, \ldots, T \\
& s r_{t}-s r_{t-1} \geq-\mathrm{d} q^{\max } ; \quad \forall t=1, \ldots, T
\end{aligned}
$$

\subsubsection{Technical constraints}

Technical constraints usually refer to those restrictions caused by certain inherent characteristics of the plant generation equipment and hydraulic system. In this paper, maximum and minimum reservoir volumes and water discharges are considered. The former are given by (19) $-(20)$; whereas the latter are implicit in (4)-(6). In the cases where the re-regulation reservoir is considered, maximum and minimum reservoir volumes (21)-(22) as well as maximum water discharge (23) are also considered.

$$
\begin{aligned}
& v_{t} \leq v_{\max } ; \quad \forall t=1, \ldots, T \\
& v_{t} \leq v_{\min } ; \quad \forall t=1, \ldots, T \\
& v r_{t} \leq v r_{\max } ; \quad \forall t=1, \ldots, T \\
& v r_{t} \geq v r_{\min } ; \quad \forall t=1, \ldots, T \\
& s r_{t} \leq s r_{\max } ; \quad \forall t=1, \ldots, T
\end{aligned}
$$

\subsubsection{Pump characteristic}

The pump is assumed to operate in a fixed-speed mode; i.e. only one operating point $(q b, p b)$ is considered. The equations used to model the pump (24)-(26) include a binary variable in order to consider the option of starting-up and shutting-down the pump.

$$
\begin{aligned}
& q p_{t}=u p_{t} q b ; \quad \forall t=1, \ldots, T \\
& p p_{t}=u p_{t} p b ; \quad \forall t=1, \ldots, T
\end{aligned}
$$

$u p_{t} \in\{0,1\} ; \quad \forall t=1, \ldots, T$

An additional constraint (27) must be taken into account in the cases where pumping capability is considered in order to eliminate the option of simultaneously pumping and generating.

$u_{t}+u p_{t} \leq 1 ; \quad \forall t=1, \ldots, T$ 


\section{Case study}

The models described in the previous section have been applied in a real hydropower plant located in the Northwest area of Spain. Main power plant data are included in Table 1.

Seven power-discharge curves, each corresponding to a value of the reservoir volume, were obtained from the reservoir curve and the efficiency hill curves of a Francis turbine with a specific speed similar to that of the power plant turbine. The efficiency hill curves were taken from [19]. The friction head losses in the conduits were neglected since, according to the available data, in the worst case they are lower than $1 \%$ of the nominal gross head. The tail water level variation was also neglected due to its small magnitude in comparison with the range of gross heads. Seven flow values were considered for each reservoir volume to build the power-discharge curves, as it is shown in Fig. 1; reservoir volumes in this figure are expressed in millions of cubic metres. Each of these curves was approximated by a linear function according to (3) and, from these approximations, both the slope and minimum power $\left(r, p_{\min }\right)$ were parametrized in terms of the reservoir volume by means of a linear regression.

In order to confirm that the influence of the head variation in the power plant revenue could be neglected, a sensitivity analysis was carried out with an optimization model similar to that used in [6], where the plant generation characteristic was modelled according to [13]. The results demonstrated that considering the head variation during the optimization process does not have a significant influence on the power plant revenue within a monthly time frame, whereas it considerably increases the computational burden of the problem. This is due to the small range of operating heads in comparison to the total gross head (see Table 1),

A historical series of monthly inflows to the reservoir of 35 years duration has been used in this paper. It was taken from [20] and corresponds to the hydrological years $1972-73$ to 2007-08; the hydrological year 1985-86 was eliminated due to the lack of data. A statistical analysis of the series has been done following the recommendation of [21] on the classification of hydrological years in three different categories, according to the annual runoff volumes: dry, normal and wet. As it can be seen in Fig. 2, the histogram of the annual water inflows distribution resembles that of a Weibull distribution, which confirms the results of [22]. The maximum likelihood method was used to obtain the range of the scale and shape parameters of the distribution. The scale parameter was taken as the average value of its range. The shape parameter was selected so that the number of years of the series belonging to each category (dry, normal and wet) was as homogeneous as possible.

Additionally, a historical series of flows released through the turbines and reservoir levels of 21 years duration was available for the study. As it can be seen in Fig. 3, there exists a strong correlation between the annual released flows and the annual water inflows. The twenty-one years of released flows have also been classified in three different categories (dry, normal and wet), each with the

Table 1

Power plant data.

\begin{tabular}{ll}
\hline Number of units & 1 \\
\cline { 1 - 1 } Maximum water flow & $25.7 \mathrm{~m}^{3} / \mathrm{s}$ \\
\hline Maximum power output & $61.14 \mathrm{MW}$ \\
Minimum power output & $9.91 \mathrm{MW}$ \\
Maximum gross head & $280.00 \mathrm{~m}$ \\
Minimum gross head & $268.50 \mathrm{~m}$ \\
\hline
\end{tabular}

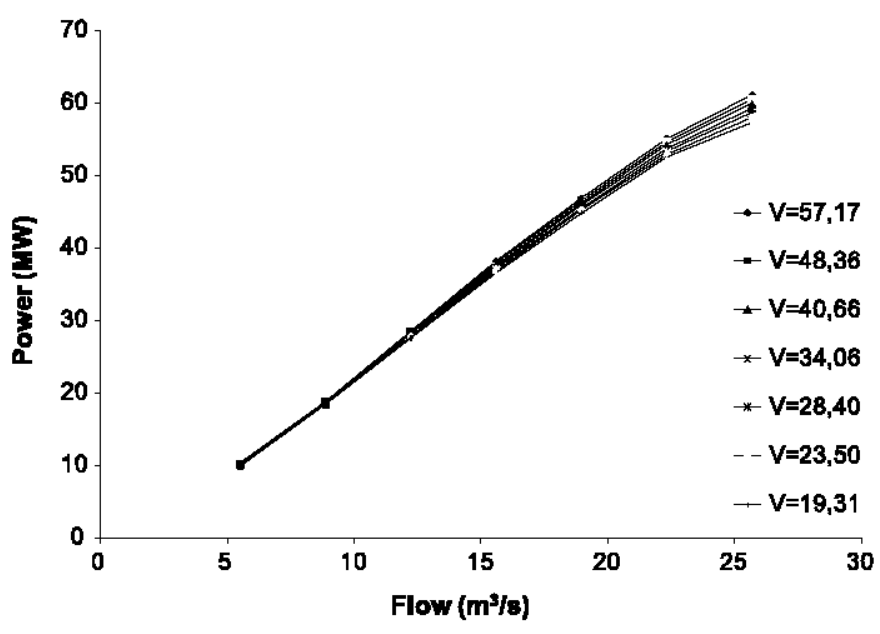

Fig. 1. Power-discharge curves.

same probability (0.33), from the derived correlation equation and the Weibull distribution; average monthly released flows for each month and each category as well as average reservoir volumes have been obtained from the available data.

Previously described optimization models have been used to estimate, within a one-month time horizon, the economic impact of the minimum environmental flow and maximum ramp rate constraints as well as the contribution of the re-regulation reservoir and the pumping capability to reducing the economic impact caused by the fulfilment of these constraints. The economic impact of the environmental constraints is estimated in each case by comparing the revenue of the hydropower producer with and without considering said constraints, obtained as a result of the first and second optimization models, respectively. In turn, the contribution of the re-regulation reservoir and the pumping capability to reducing the economic impact of the environmental constraints is estimated by comparing the results obtained with the second, third and fourth optimization models.

In order to explore the sensitivity to each environmental constraint, the calculations have been done for several values of the parameter defining the constraints. Five different values of both the minimum environmental flow and maximum ramp rate have been used. The values of $q_{\mathrm{ec}}$ are between the minimum and maximum values indicated in the draft version of the Minho-Sil Hydrological Plan [23], which corresponds to the river basin where the hydropower plant is located. In turn, the values of $\mathrm{d} q^{\max }$ are between the 10 and $100 \%$ of the value indicated in the Galician river fishing Decree 130/1997 [24] $\left(15 \mathrm{~m}^{3} / \mathrm{s} / \mathrm{h}\right)$.

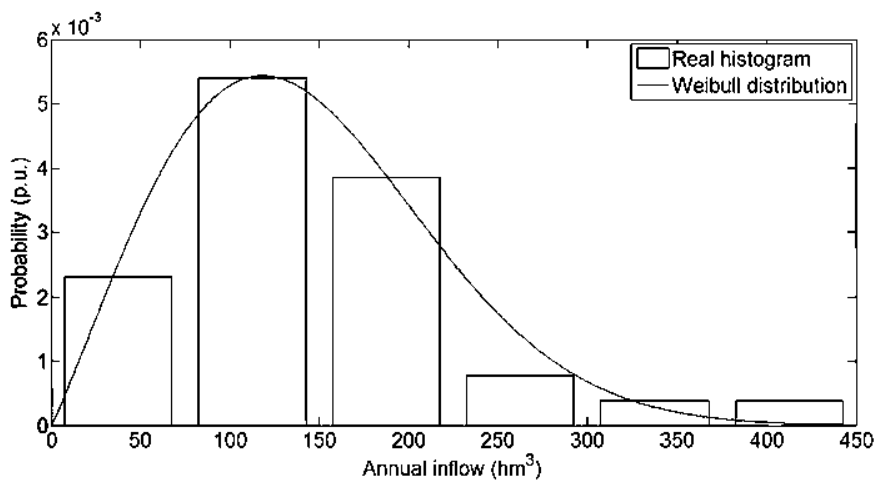

Fig. 2. Histogram and probability distribution of annual water inflows. 


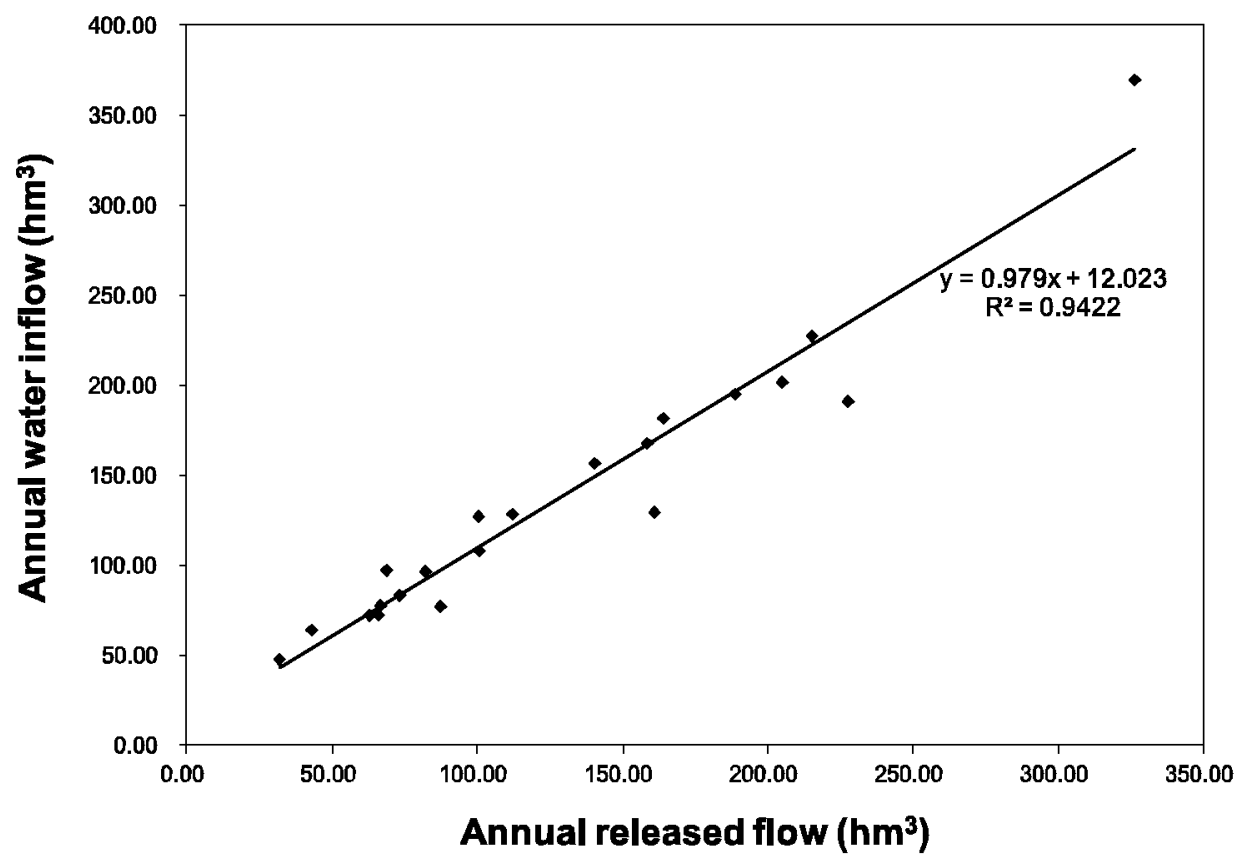

Fig. 3. Correlation between annual water inflows and released flows.

Energy prices used to carry out this analysis correspond to December 2009 and were taken from [25]. Average released flow corresponding to December has been taken as water inflow; a uniform hourly distribution throughout the month has been assumed. Both the initial and final reservoir volumes have been assumed to be equal to the average reservoir volume during December (11); in this way, it is guaranteed that the hydropower plant will release the whole water inflow (average released flow in December) either through the turbines or the bottom outlets. The power-discharge curve corresponding to the average reservoir volume in December has been used. A global efficiency of the pump-turbine cycle equal to $76.3 \%$ has been assumed.

The optimization models described in section 2 have been implemented in various computers with $1.9 \mathrm{GHz}$ processor and 4.0 GB of RAM, using CPLEX 12 [26] under GAMS. Given the huge number of scenarios analysed and the number of binary variables involved in the described models, it was necessary to limit to $900 \mathrm{~s}$ the maximum amount of time that CPLEX could consume to reach in each individual problem a $0.1 \%$ gap between the best integer objective and the objective of the best node remaining; it should be noted that CPLEX 12 uses a branch and cut algorithm to solve problems with integer variables [26]. The first two described models reached the above-mentioned gap within the prespecified time. The third model used up the pre-specified time in all cases where $v r_{\max }$ is lower than $0.4 \mathrm{hm}^{3}$ or $\mathrm{dq}^{\max }$ is lower than $50 \%$ of the value indicated in [24]; in the worst case, the model reached a $0.29 \%$ gap. The fourth model used up the prespecified time in all cases, a maximum $1.77 \%$ gap being obtained in the worst case.

The maximum reduction in revenue due to the fulfilment of the environmental constraints (without considering the influence of the re-regulation reservoir and the pumping capability) ranges from $14 \%$, considering the released flow corresponding to a wet year, to $39 \%$, considering the released flow corresponding to a dry year. Table 2 shows the expected revenue for all combinations of environmental constraints and the released flow corresponding to a dry year. The expected revenue without considering any environmental constraint is $\mathbf{2 7 8 0 1 1 . 9 0} €$. It should be noted the revenue are called "expected" since average released flow and reservoir volume have been used.

In Fig. 4, it can be seen the evolution of the re-regulation reservoir during the first week of the month for two different values of $v r_{\max }$ and three different ramp rate values. In this figure, it can be seen that in the case where $v r_{\max }=0.2 \mathrm{hm}^{3}$, the reregulation reservoir reaches every day the maximum and minimum volumes for all ramp rate values, whereas in the case $v r_{\max }=0.5 \mathrm{hm}^{3}$, the evolution is considerably less abrupt; it only reaches three times the maximum volume for the lowest ramp rate.

In Fig. 5, it can be seen the increase in revenue, or the reduction in the economic impact, with respect to the case where environmental constraints are fulfilled but neither re-regulation reservoir nor pumping capability are considered, for all combinations of environmental constraints and two different values of $v r_{\max }(0.2$ and $0.4 \mathrm{hm}^{3}$ ). It is important to point out that for usable capacities greater than $0.3 \mathrm{hm}^{3}$, i.e. $v r_{\max }>0.4 \mathrm{hm}^{3}$ (an unusable volume of $0.1 \mathrm{hm}^{3}$ has been considered in all cases), the reduction in the economic impact of the environmental constraints is barely sensitive to the increase of said capacity; the results corresponding to $v r_{\max }>0.4 \mathrm{hm}^{3}$ are almost the same as those of Fig. 5 (right). The increase in revenue for capacities greater than $0.3 \mathrm{hm}^{3}$ ranges from 18.6 (considering the released flow corresponding to a wet year) to $61.89 \%$ (considering the released flow corresponding to a dry year); as it can be seen in Fig. 5, the increase in revenue is considerably higher in the cases where the released flow corresponds to a dry year. These results demonstrate that a small re-regulation reservoir could help to fulfil the environmental constraints and to reduce their economic impact.

Table 2

Expected revenue $(€)$ (prices of December 2009, dry year).

\begin{tabular}{|c|c|c|c|c|c|}
\hline & $\mathrm{dq} q^{\max }=2.5$ & $\mathrm{dq}^{\max }=5.0$ & $\mathrm{~d} q^{\max }=7.5$ & $\mathrm{~d} q^{\max }=10.0$ & $\mathrm{~d} q^{\max }=15.0$ \\
\hline$q_{\mathrm{ec}}=0.149$ & 192071.42 & 224715.36 & 239994.46 & 248071.88 & 256648.76 \\
\hline$q_{\mathrm{ec}}=0.235$ & 186764.59 & 218416.91 & 233105.73 & 240768.19 & 249070.09 \\
\hline$q_{\mathrm{ec}}=0.322$ & 181418.17 & 212114.51 & 225990.76 & 233285.82 & 241446.84 \\
\hline$q_{\mathrm{ec}}=0.408$ & 175977.84 & 205651.84 & 218885.58 & 225852.73 & 233631.81 \\
\hline$q_{\mathrm{ec}}=0.494$ & 170490.34 & 199143.40 & 211583.97 & 218167.51 & 225768.56 \\
\hline
\end{tabular}



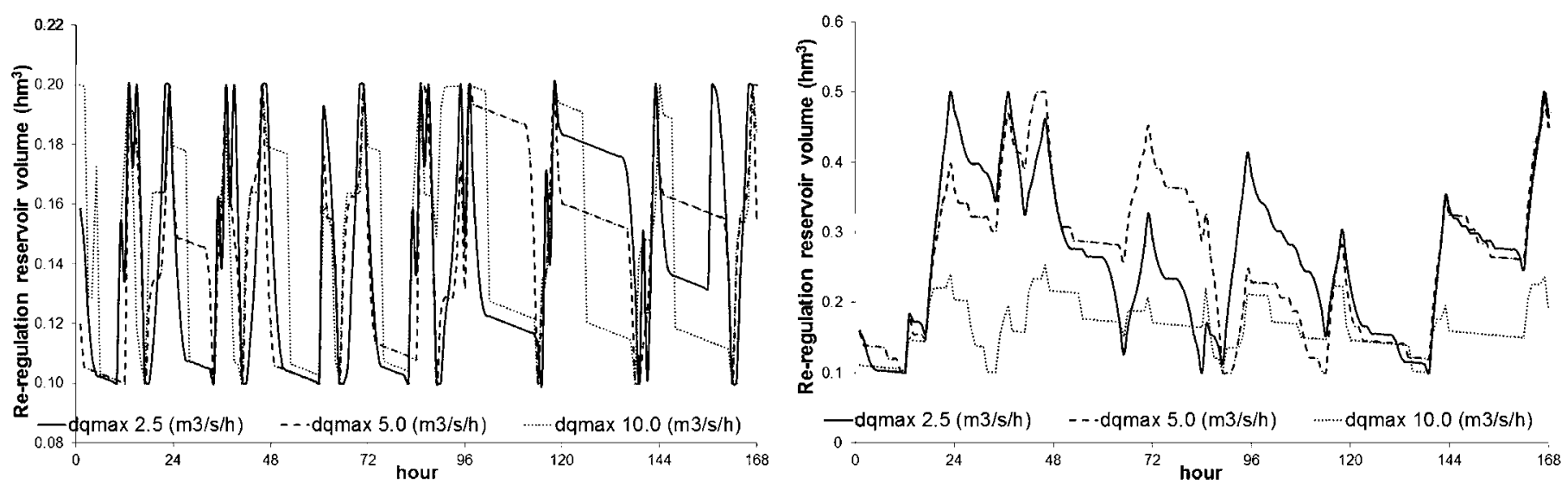

Fig. 4. Re-regulation reservoir volume for $v r_{\max }=0.2 \mathrm{hm}^{3}$ (left) and $v r_{\max }=0.5 \mathrm{hm}^{3}$ (right).
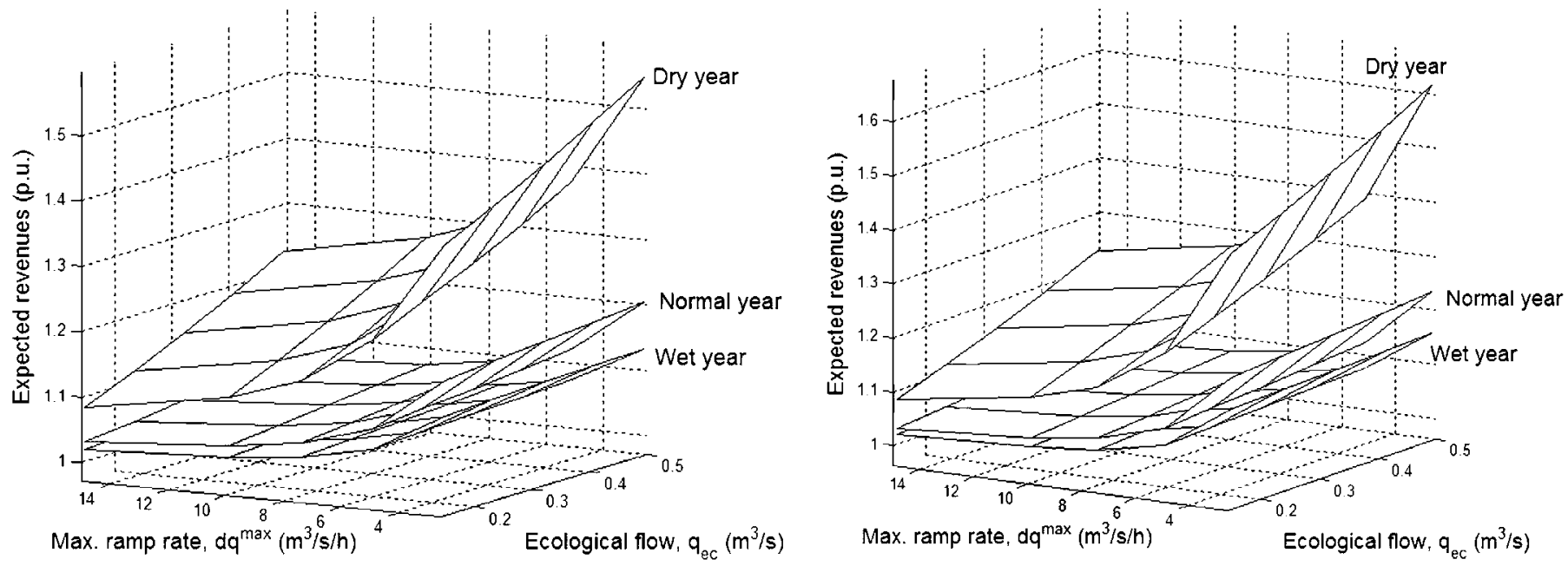

Fig. 5. Expected revenue (in per unit values) for $v r_{\max }=0.2 \mathrm{hm}^{3}$ (left) and $v r_{\max }=0.4 \mathrm{hm}^{3}$ (right).

In Fig. 6, it can be seen the evolution of the re-regulation reservoir during the first week of the month for two different values of $v r_{\max }$ and three different values of $\mathrm{dq} q^{\max }$, in the case where pumping capability is considered. In contrast to Fig. 4, an important fluctuation of the volume can be observed for both values of $v r_{\max }$. This fluctuation indicates that the power plant takes advantage of the re-regulation reservoir capacity in order to pump water during off-peak hours and use it for power generation during peak hours so that the revenue is maximized.

The increase in revenue (with respect to the case where the environmental constraints are fulfilled but neither re-regulation reservoir nor pumping capability are considered) obtained as
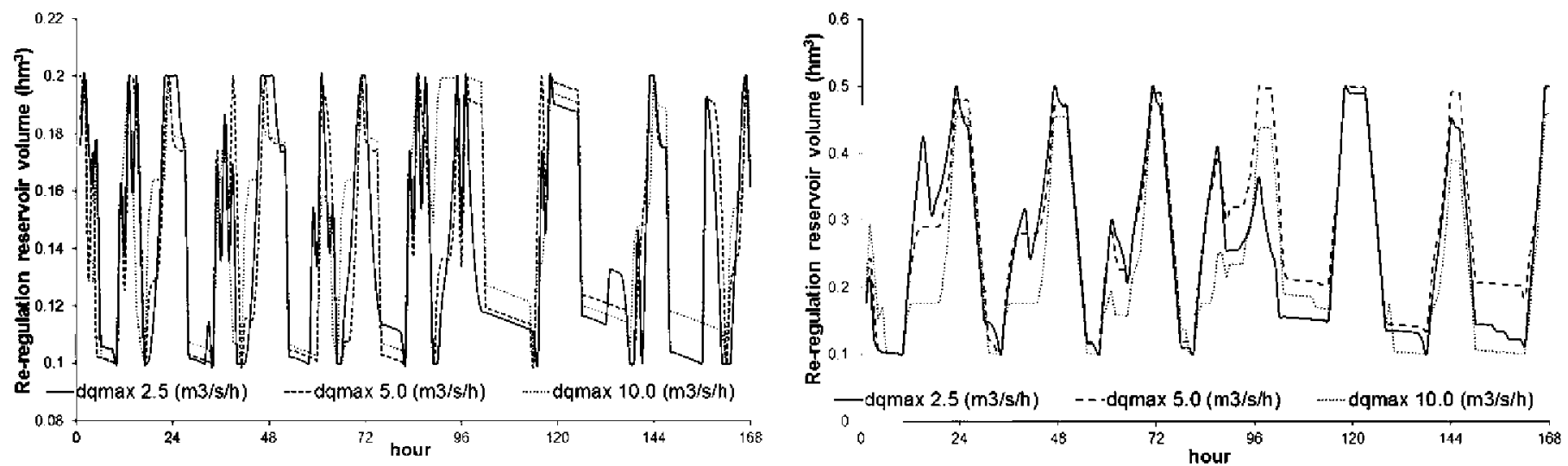

Fig. 6. Re-regulation reservoir volume for $v r_{\max }=0.2 \mathrm{hm}^{3}$ (left) and $v r_{\max }=0.5 \mathrm{hm}^{3}$ (right), considering pumping capability. 

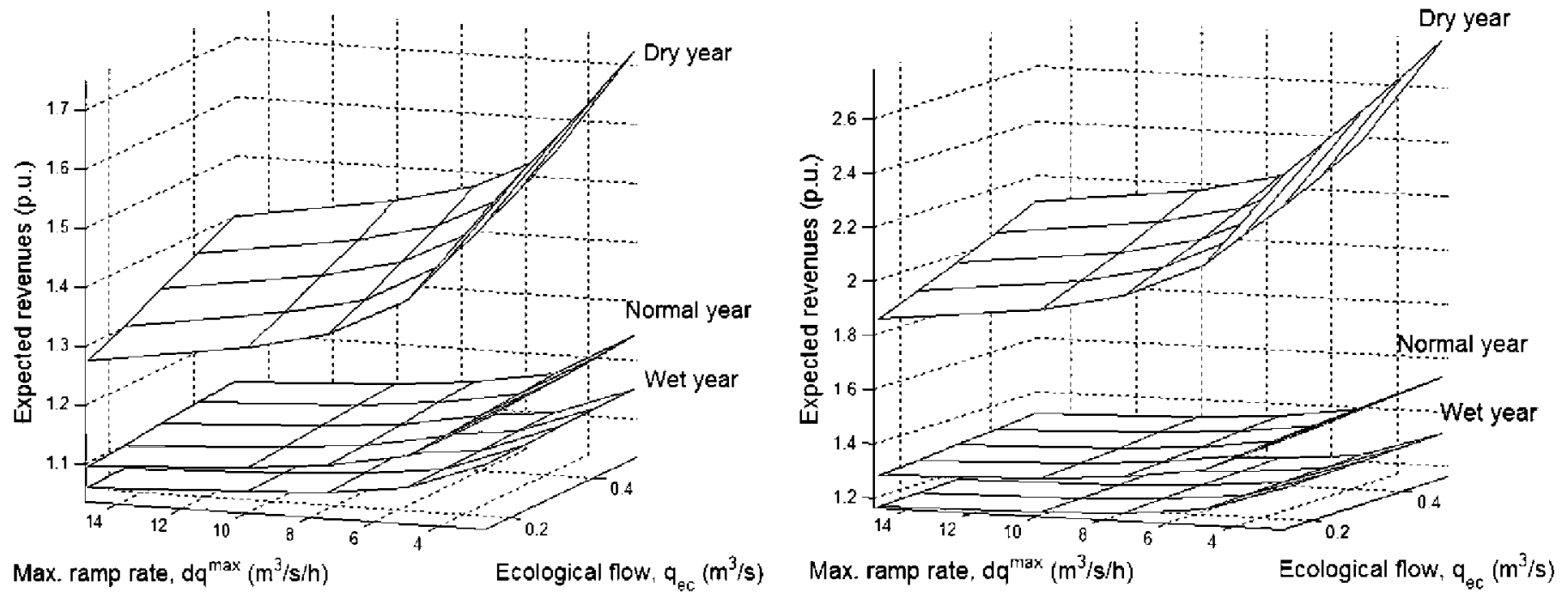

Max. ramp rate, $d q^{\max }\left(\mathrm{m}^{3} / \mathrm{s} / \mathrm{h}\right)$

Ecological flow, $q_{\mathrm{BC}}\left(\mathrm{m}^{3} / \mathrm{s}\right)$

Fig. 7. Expected revenue (in per unit values) for $v r_{\max }=0.2 \mathrm{hm}^{3}$ (left) and $v r_{\max }=0.75 \mathrm{hm}^{3}$ (right), considering pumping capability.
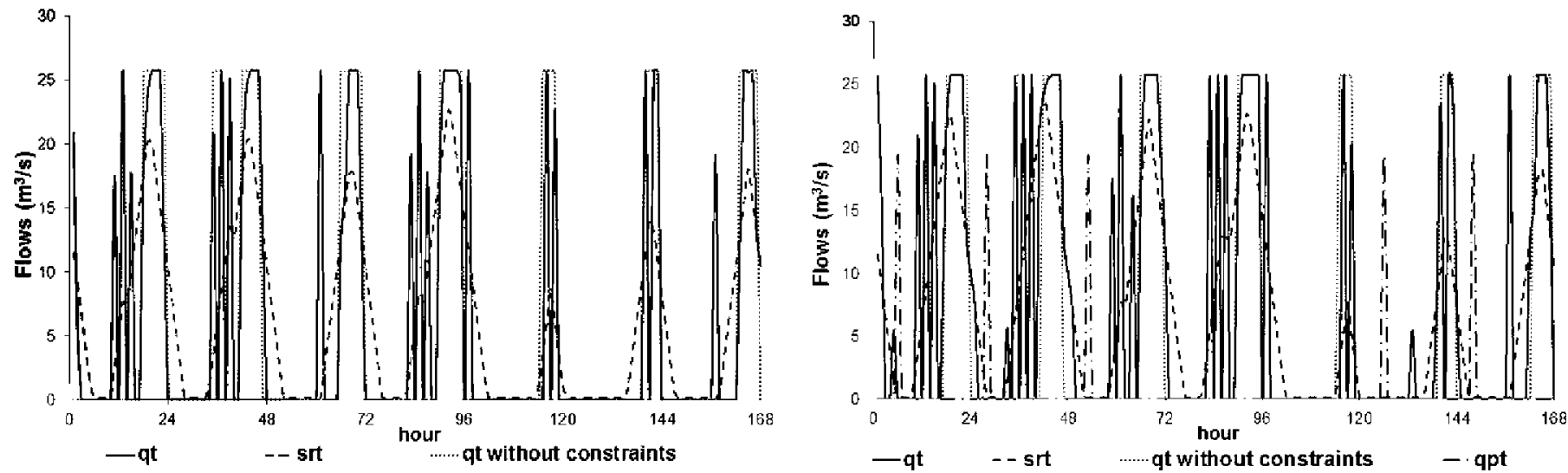

Fig. 8. Water flows used for generation $\left(q_{t}\right)$, pumping $\left(q p_{t}\right)$ and released to the river ( $\left.s r_{t}\right)$ without (left) and with pumping capability (right).

a consequence of adding pumping capability increases as the reregulation reservoir capacity increases within the range of $v r_{\max }$ analysed $\left(0.2,0.3,0.4,0.5,0.75,1\right.$ and $\left.1.5 \mathrm{hm}^{3}\right)$. The results obtained for $v r_{\max }$ equal to 0.2 and $0.75 \mathrm{hm}^{3}$ can be seen in Fig. 7. It is interesting to note that, in an analogous way to the case where pumping capability was not considered (Fig. 5), the increase in revenue is higher in the cases where the released flow corresponds to a dry year. These results demonstrate that the addition of pumping capability does not only allow eliminating the economic impact of the environmental constraints but also increasing the power plant revenue.

In order to analyse the influence of both the re-regulation reservoir and the pumping capability on the power plant operation, the hourly water flows used for both generation and pumping as well as those released to the river during the first week of the month have been depicted in Fig. 8 in the case where $v r_{\max }=0.2 \mathrm{hm}^{3}$ and $\mathrm{dq} q^{\max }=2.5 \mathrm{~m}^{3} / \mathrm{s} / \mathrm{h}$. For the sake of comparison, the hourly flows used for generation in the reference case (without re-regulation reservoir, pumping capability and environmental constraints) have also been included in the figure. As it can be seen in the figure, the power plant tries to generate in the same periods as in the reference case; however, this is not always possible in the case where pumping capability is not considered. If pumping capability is considered, the plant generates during the same periods as in the reference case and other additional periods, thus taking advantage of the water pumped during off-peak hours and increasing the revenue.

An analysis similar to the one previously described has been carried out within a one-year time frame. For this purpose, only one

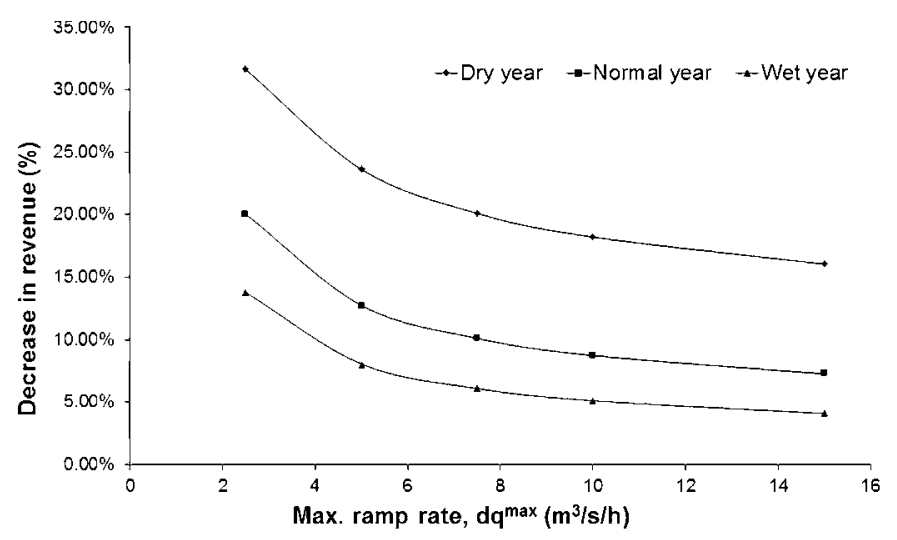

Fig. 9. Reduction in annual revenue due to the fulfilment of environmental constraints. 

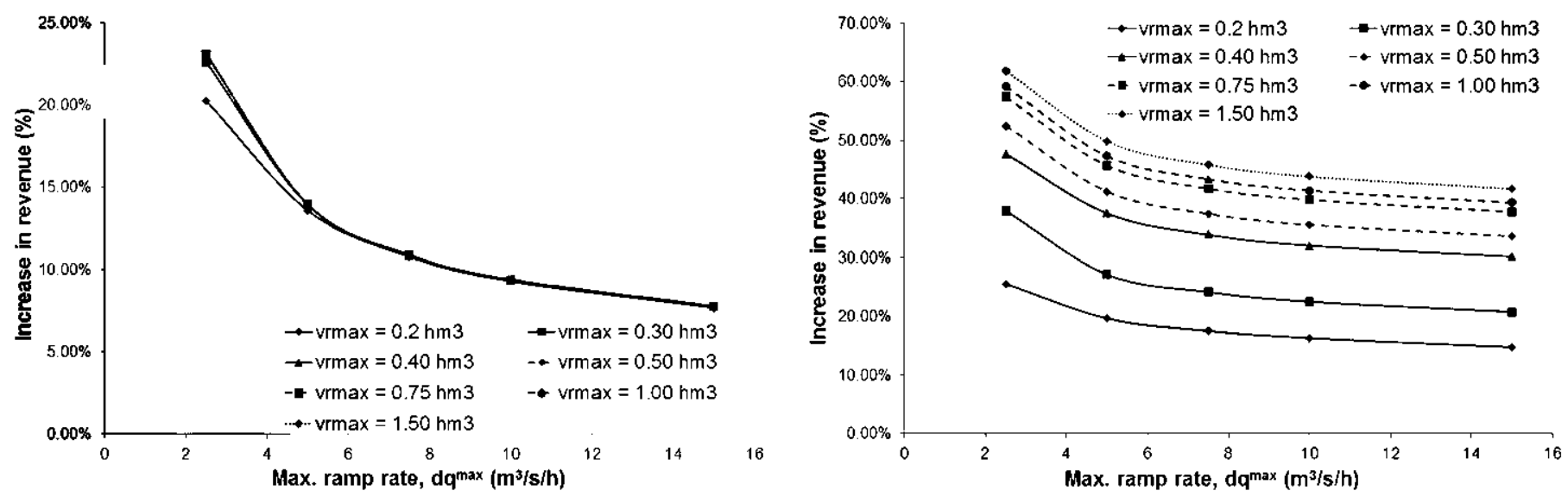

Fig. 10. Expected annual increase in revenue with re-regulation reservoir (left) and re-regulation reservoir and pumping capability (tight).

value of $q_{\mathrm{ec}}$ has been used for each month (the one that is specified in [23]). Regarding $d q^{\max }$ and $v r_{\max }$ the same values as in the previous analysis have been used; unlike the minimum environmental flow, there is a certain lack of definition about the values of maximum ramp rates in Spanish regulations. Initial and final reservoir volumes of each month have been assumed to be equal to the average reservoir volume during the corresponding month. Average released flows for each month and each category have been taken as water inflows. The maximum amount of time that CPLEX could consume to reach in each individual problem a $0.1 \%$ gap was limited to $200 \mathrm{~s}$. Consequently, the obtained gaps increased in comparison to those previously mentioned; nevertheless, said increase turned out to be barely significant (around $0.01 \%$ as an average value).

Firstly, the reduction in revenue due to the fulfilment of environmental constraints was calculated for the three different categories of hydrological years considered. As it can be seen in Fig. 9, the reduction in revenue is considerably higher in the case where the released flow corresponds to a dry year. As it seems obvious, the less amount of water available to produce energy, the more important is to have flexibility to manage the water in such a way that the maximum amount of energy is produced during peak hours.

The average increase in annual revenue with respect to the case where environmental constraints are fulfilled but neither reregulation reservoir nor pumping capability are considered, is shown in Fig. 10 for different values $\mathrm{dq}^{\max }$ and $v r_{\max }$. As it can be seen in Fig. 10 (left), for $v r_{\max }>0.4 \mathrm{hm}^{3}$ the increase in revenue is barely sensitive to the increase of the re-regulation reservoir capacity, in an analogous way to the analysis carried out within a one-month time horizon (Fig. 5). By contrast, as it is shown in Fig. 10 (right), the increase in revenue is considerably sensitive to the increase of the re-regulation reservoir capacity when pumping capability is added; nevertheless, as it seems logical, the sensitivity decreases significantly as $v_{\max }$ increases.

\section{Conclusion}

In this paper, the contribution of re-regulation reservoirs to reducing the economic impact of the environmental constraints on hydropower operation has been studied in detail by means of revenue-driven optimization models. The obtained results demonstrate that the construction of a small re-regulation reservoir downstream of a hydropower plant may allow eliminating the economic impact caused by the fulfilment of certain environmental constraints. Specifically, in the case studied in the paper, a reregulation reservoir with a capacity sufficient to store the flow discharged through the power plant turbines during $4 \mathrm{~h}$ (assuming full load flow) suffices to eliminate the economic impact in all scenarios analysed.

Additionally, the advantages that could be obtained by adding pumping capability between the re-regulation reservoir and the main one have been explored. The obtained results show that the addition of pumping capability does not only allow eliminating the economic impact of the environmental constraints but also increasing the power plant revenue.

Finally, as a future line of work (already in progress), it would be interesting to carry out a detailed economic feasibility study of both the construction of a re-regulation reservoir and the addition of pumping capability.

\section{Acknowledgement}

This work was supported in part by the Spanish Ministry of Science and Innovation under the Project CGL2009-14258. The authors also wish to thank the company Gas Natural Fenosa Engineering (formerly SOCOIN) for providing us the technical data of the hydropower plant analyzed in the paper.

\section{Nomenclature}

$\mathrm{d} q^{\max } \quad$ Maximum ramp rate $\left(\mathrm{m}^{3} / \mathrm{s} / \mathrm{h}\right)$.

$f_{c} \quad$ Conversion factor $\left(0.0036 \mathrm{hm}^{3} / \mathrm{h} / \mathrm{m}^{3} / \mathrm{s}\right)$.

ltr Maximum value of $g t_{t}\left(\mathrm{~m}^{3} / \mathrm{s}\right)$.

90 Initial flow discharge through the turbines $\left(\mathrm{m}^{3} / \mathrm{s}\right)$

qb Design pump flow $\left(\mathrm{m}^{3} / \mathrm{s}\right)$.

$q_{\mathrm{ec}} \quad$ Minimum environmental flow $\left(\mathrm{m}^{3} / \mathrm{s}\right)$.

$q_{\text {min }} \quad$ Minimum flow discharged through the turbines for power generation $\left(\mathrm{m}^{3} / \mathrm{s}\right)$.

$q p_{t} \quad$ Pumped flow in period $t\left(\mathrm{~m}^{3} / \mathrm{s}\right)$.

$q_{t} \quad$ Flow discharged through the turbines in period $t\left(\mathrm{~m}^{3} / \mathrm{s}\right)$.

qtr $r_{t} \quad$ Flow discharged through the turbines (over $q_{\min }$ ) in period $t\left(\mathrm{~m}^{3} / \mathrm{s}\right)$.

pb Design pump power consumption (MW).

$p_{\text {min }} \quad$ Minimum power output (MW)

$p p_{t} \quad$ Power used for pumping in period $t(\mathrm{MW})$.

$p_{t} \quad$ Power output in period $t$ (MW).

$r \quad$ Slope of the power-discharge line $\left(\mathrm{MW} / \mathrm{m}^{3} / \mathrm{s}\right)$.

$s_{0} \quad$ Initial flow released through the bottom outlets of the main reservoir $\left(\mathrm{m}^{3} / \mathrm{s}\right)$. 
Initial flow released to the river from the re-regulation reservoir $\left(\mathrm{m}^{3} / \mathrm{s}\right)$.

$s r_{t} \quad$ Flow released to the river from the re-regulation reservoir $\left(\mathrm{m}^{3} / \mathrm{s}\right)$.

$s r_{\max } \quad$ Maximum flow that can be released from the reregulation reservoir $\left(\mathrm{hm}^{3}\right)$.

$s_{t} \quad$ Flow released through the bottom outlets of the main reservoir $\left(\mathrm{m}^{3} / \mathrm{s}\right)$.

$T \quad$ Number of hourly periods considered within the time horizon.

$u_{t} \quad$ Binary variable used to model the plant generation characteristic $\{0,1\}$.

$u p_{t} \quad$ Binary variable used to model the pump characteristic $\{0,1\}$.

$V_{0} \quad$ Initial volume of the main reservoir $\left(\mathrm{hm}^{3}\right)$.

$v_{\max } \quad$ Maximum reservoir volume $\left(\mathrm{hm}^{3}\right)$.

$v_{\min } \quad$ Minimum reservoir volume $\left(\mathrm{hm}^{3}\right)$.

$v_{t} \quad$ Reservoir volume at the end of period $t\left(\mathrm{hm}^{3}\right)$.

$V_{T} \quad$ Final volume of the main reservoir $\left(\mathrm{hm}^{3}\right)$.

$V r_{0} \quad$ Initial volume of the re-regulation reservoir $\left(\mathrm{hm}^{3}\right)$.

$v r_{\text {max }} \quad$ Maximum re-regulation reservoir volume $\left(\mathrm{hm}^{3}\right)$.

$v r_{\text {min }}$ Minimum re-regulation reservoir volume $\left(\mathrm{hm}^{3}\right)$.

$v r_{t} \quad$ Re-regulation reservoir volume at the end of period $t$ $\left(\mathrm{hm}^{3}\right)$.

$V r_{T} \quad$ Final volume of the re-regulation reservoir $\left(\mathrm{hm}^{3}\right)$.

$w_{t} \quad$ Water inflow to the reservoir in period $t\left(\mathrm{~m}^{3} / \mathrm{s}\right)$.

$\pi_{t} \quad$ Energy price in period $t(€ / \mathrm{MWh})$.

\section{References}

[1] Spanish Ministry of Environment, Order ARM/2656/2008. Available [in Spanish]: http://www.boe.es/boe/dias/2008/09/22/pdfs/A38472-38582.pdf [accessed 24.06.12]

[2] Lu S, Makarov YV, Zhu Y, Lu N, Kumar NP, Chakrabarti BB. Unit commitment considering generation flexibility and environmental constraints, proceedings of the IEEE power and energy society general meeting. Minneapolis, Minnesota, US; July 25-29, 2010.

[3] Harpman DA. Assessing the short-run economic cost of environmental constraints on hydropower operations at glen canyon dam. Land Economics 1999:75(3):390-401.

[4] Kotchen M], Moore MR, Lupi S, Rutherford ES. Environmental constraints on hydropower: an ex-post benefit-cost analysis of dam relicensing in Michigan. Land Economics 2006;82(3):384-403.

[5] Niu S, Insley M. On the economics of ramping rate restrictions at hydro power plants: balancing profitability and environmental costs. Available: http:// www.arts.uwaterloo.ca/\%7Eminsley/ramping\%20rate\%20paper\%20Jan\%203\% 202011.pdf; 2010 [accessed 24.06.12].

[6] Pérez-Díaz JI, Wilhelmi JR. Assessment of the economic impact of environmental constraints on short-term hydropower plant operation. Energy Policy 2010;38(2):7960-70.
[7] Richter BD. Thomas GA. Restoring environmental flows by modifying dam operations, Ecol Andiety 2007;12(1). art.12.

[8] Olivares M.A., Optimal hydropower reservoir operation with environmental requirements, PhD thesis, Davis: College of Engineering. University of Calfornia, Davis, 2008.

[9] Madani K, Lund JR. Modelling California's high-elevation hydropower systems in energy units. Water Resour Res 2009;45. W09413.

[10] Nazari ME, Ardehali MM, Jafari S. Pumped-storage unit commitment with considerations for energy demand, economics, and environmental constraints. Energy 2010;35(10):4092-101.

[11] Chang GW, Aganagic M, Waight JG, Medina J, Burton T, Reeves S, et al. Experiences with mixed integer linear programming based approaches on short-term hydro scheduling. IEEE T Power Syst 2001;16(4):743-9.

[12] García-Conzález J, Moraga R, Matres R, Mateo A. Stochastic joint optimization of wind generation and pumped-storage units in an electricity market. IEEE $T$ Power Syst 2008;23(2):460-7.

[13] Conejo AJ, Arroyo JM, Contreras J, Apolinar F. Self-scheduling of a hydro producer in a pool-based electricity market. IEEE T Power Syst 2002;17(4): $1265-72$.

[14] Pérez-Díaz JI, Wilhelmi JR, Arévalo Muñoz L. Optimal short-term operation schedule of a hydropower plant in a competitive electricity market. Energ Convers Manage 2010:51(12):2955-66.

[15] Catalao JPS, Pousinho HMI, Mendes VMF. Hydro energy systems management in Portugal: profit-based evaluation of mixed-integer nonlinear approach. Energy 2011;36(1):500-7.

[16] Arce A, Ohishi T, Soares S. Optimal dispatch of generating units of the Itaipú hydroelectric plant. IEEE Trans Syst 2002;17(1):154-8.

[17] Diniz AL, Piñeiro-Maceira ME. A four-dimensional model of hydro generation for the short-term hydrothermal dispatch problem considering head and spillage effects. IEEE T Power Syst 2008;23(3):1298-308.

[18] Borghetti A D'Ambrosio C Lodi A Martello S. A milp approach for short-term hydro scheduling and unit commitment with head-dependent reservoir. IEEE T Power Syst 2008;23(3).

[19] US Department of the Interior. Bureau of reclamation, selecting hydraulic reaction turbines. A Water Resources Technical Publication, Engineering Monograph No. 20. Available: http://www.usbr.gov/pmts/hydraulics_lab/ pubs/EM/EM20.pdf; 1976 [accessed 24.06.12]

[20] Website of the Centre for Studies and Experimentation of Public Works of Spain, CEDEX [in Spanish]: http://hercules.cedex.es/anuarioaforos/default.asp [accessed 24.06.12].

[21] Stillwater Sciences. confluence research and consulting and heritage research associates, Inc., scientific approaches for evaluating hydroelectric project effects. Available: http://www.hydroreform.org/sites/www.hydroreform.org/ files/HRC\%20Science\%20Guide.pdf; 2006 [accessed 24.06.12].

[22] Pérez González, M.E. and Sanz Donaíre, JJ. esAspectos geográficos de las distribuciones estadisticas ajustadas a las series temporales rellenadas de totales anuales de precipitación española, NIMBUS, No. 7-8, p. 135-59.

[23] Demarcación Hidrográfica del Miño-Sil, Hydrological Plan, 2010 (draft). Available [in Spanish]: http://www.chminosil.es/contenido.php\%3fmod\%3d0\% 26id0\%3d4\%26id1\%3d122 [accessed 24,06.12].

[24] Royal Decree 130/1997, May 14th, by which regulations for river fishing and continental water ecosystems are approved. Conselleria de Agricultura y Montes, Xunta de Galicia. Available [in Spanish]: http://www.xunta.es/Doc/ Dog1997.nsf/FichaContenido/7642\%3fOpenDocument [accessed 24.06.12]

[25] Website of the Spanish Electrical System Operator: www.ree.es [accessed 24.06.12].

[26] GAMS. The solver manuals. Washington DC, USA: GAMS Development Corporation; 2011. 